\title{
Equity Valuation with Heterogeneous Beliefs
}

\author{
Niu Weining \\ School of Business, Beijing International Studies University, Beijing 100024, China
}

Received January 31, 2021; Revised March 9, 2021; Accepted April 9, 2021

\begin{abstract}
Cite This Paper in the following Citation Styles
(a): [1] Niu Weining, "Equity Valuation with Heterogeneous Beliefs," Universal Journal of Accounting and Finance, Vol. 9, No. 2, pp. 204 - 209, 2021. DOI: 10.13189/ujaf.2021.090209.
\end{abstract}

(b): Niu Weining (2021). Equity Valuation with Heterogeneous Beliefs. Universal Journal of Accounting and Finance, 9(2), 204 - 209. DOI: 10.13189/ujaf.2021.090209.

Copyright $\odot 2021$ by authors, all rights reserved. Authors agree that this article remains permanently open access under the terms of the Creative Commons Attribution License 4.0 International License

\begin{abstract}
Residual income model in equity valuation has emerged as a useful reference for investment decisions on account of its theoretical foundations for analytical accounting research and also the basis of modelling for empirical study on value relevance. However, since investors have disagreement on firm's future earnings, it may have an effect on firm's evaluation and hence affect stock price. The paper extends the residual income model by incorporating investors' heterogeneous beliefs on the persistence of residual income, and then tests the theoretical findings through numerical simulation. The model implies that the relation between stock price and heterogeneous beliefs depends on the sign of residual income, and the impact of informed traders on stock price relies on the interaction effect of heterogeneous beliefs and residual income. The numerical simulation results prove that under the circumstance of positive heterogeneous beliefs, if residual income is also positive, stock price has a positive relation with heterogeneous beliefs and amount of informed investor; while if residual income is negative, stock price has a negative relation with heterogeneous beliefs and informed trading. The findings of the paper provide some useful theoretical implications on the effect of heterogeneous beliefs on equity valuation via residual income framework. Research limitations mainly exist in the strict theoretical assumptions, which can be loosen in further researches to make the model closer to real market.
\end{abstract}

Keywords Heterogeneous Beliefs, Residual Income, Equity Valuation

\section{Introduction}

Equity valuation is a core issue in corporate finance research area, and there are plenty of theoretical models for valuation, e.g. Dividend Discount Model (DDM), Free Cash-Flow Model (FCFM), Residual Income Model (RIM), Options-Based Model (ROM), etc. In these established models, RIM as an advanced formula of equity valuation, especially the valuation via Linear Information Dynamics (LID) which has more rich findings and broader applications, not only provides theoretical foundations for analytical accounting research, but also offers the basis of modelling for empirical study on value relevance. Therefore, RIM has emerged as a very useful reference for investment decisions.

Based on DDM, the assumptions of clean surplus relation (CSR), and a first order autoregression process AR(1), Ohlson [1] built the residual income valuation model via LID. Feltham and Ohlson [2] divided firm's activities into both financial and operating activities, and assumed that the market value of financial assets (and liabilities) equaled book value in a perfect market, and then proposed an extended model that equity value equaled the book value of financial assets (which are marked to market) plus the present value of free cash flows expected from operating activities. Feltham and Ohlson [3] applied dynamics in cash flows (cash receipts and cash investments) instead of accounting variables, and developed a new valuation model. Since then RIM has been extensively discussed in both academic research and practical application, for instance, Richardson and Tinaikar [4] provided a brief review of researches on accounting based valuation models and its applications; Zhang [5] gave a more systematic and comprehensive review on the valuation literature based on those three milestone works in the past decades, and suggested future directions for further developing valuation theory and related empirical research. However, in most of these 
literatures, investors' beliefs are assumed homogeneous.

Meanwhile, with more and more financial anomalies arisen in empirical researches, scholars have made a breakthrough in the assumption of investor's rationality. Ample literatures in behavioral finance (surveyed in Shleifer [6]; Xiong [7]) indicate that market participants are not always rational, and they have different opinions on assets' future payoff. These disagreements, also known as heterogeneous beliefs, arise from gradual information flow, limited attention and heterogeneous priors (Hong and Stein [8]). Besides, Huang et al. [9] summarized twenty four extant disagreement measurements, which based on professional forecasts, analyst forecasts, household forecasts and market information, and then proposed a partial least squares disagreement index.

Numerous theoretical models and empirical evidences have discussed the effects of heterogeneous beliefs on asset pricing and corporate decisions. For instance, Gilchrist et al. [10] analyzed the effect of stock price bubbles, which is caused by dispersion in investor beliefs and short-selling constraints, on corporate investment decisions; Smith [11] expounded the effect of lower and higher disagreement in financial markets on corporate investment; Buraschi et al. [12] described the effect of heterogeneous perceptions of aggregate consumption growth on bond and stock returns; Baker et al. [13] explained the speculation and aggregate investment under disagreement; Siganos et al. [14] discussed stock trading with divergence of sentiment; Curatola [15] assessed the optimal portfolio choice and consumption-investment problem of heterogeneous loss averse investors; Borovička [16] found the interaction between risk sharing, speculative behavior and consumption-saving choice of agents with heterogeneous beliefs under recursive preferences; Pohl et al. [17] proved that heterogeneous beliefs lead to time-varying consumption, which can help explain several asset pricing puzzles; [18-23] investigated corporate financing, capital structure, investment, acquisitions, dividend and managerial incentives under heterogeneous beliefs; etc.

Since heterogeneous beliefs among investors will affect assets' prices in financial markets and hence influence firms' decisions, how these disagreements among investors alter their valuation of stocks and then initiate speculation and alter equilibrium price is worthy of reflection. Therefore, in view of the popularity and tractability of RIM, this paper aims to imply heterogeneous beliefs in RIM framework and discuss to what extent the beliefs' effect on pricing. Through an equilibrium model, the link between heterogeneous beliefs and equity value gives rise to some testable implications. The theoretical findings are also verified by numerical simulation.

The paper is organized as follows: Section 2 describes the theoretical model, while Section 3 presents the numerical simulation, and Section 4 concludes the paper.

\section{Model}

Based on the DDM and CSR, the basic RIM proposed by Ohlson [1] expresses equity value as a function of equity book value and expected future residual income, i.e.

$$
P_{t}=B_{t}+\sum_{s=1}^{\infty} \frac{E_{t}\left(\tilde{X}_{t+s}^{a}\right)}{(1+r)^{s}}
$$

Where $P_{t}$ is the firm's equity value at date $\mathrm{t}$ (the end of period $\mathrm{t}) ; B_{t}$ is the book value of equity at date $t$; $X_{t+s}$ is the earnings in the period $t+s, s=1,2, \ldots ; \tilde{X}_{t+s}^{a}$ is the random variable of $X_{t+s}^{a}$, which is the residual income (also known as abnormal earnings) of the firm in the period $t+s ; E_{t}(\cdot)$ is the expectation operator conditional on the information available at date $t ; r$ is investor's required rate of return; and $X_{t}^{a}=X_{t}-r B_{t-1}$.

The LID approach adopted by Ohlson [1] assumes the following $\mathrm{AR}(1)$ process:

$$
\tilde{X}_{t+1}^{a}=w X_{t}^{a}+\tilde{e}_{t+1}
$$

where $0 \leq w \leq 1$ is a parameter representing the persistence of residual income from period $t$ to the next period $t+1$; and $\tilde{e}_{t+1}$, with $E\left(\tilde{e}_{t+1}\right)=0$, is a disturbance term which is not predictable at the date $t$.

Substituting AR(1) process into the RIM and simplifying, equity value as a function of book value and residual income (which are both observable at date $t$ ) is derived as

$$
P_{t}=B_{t}+\frac{w}{1+r-w} X_{t}^{a}
$$

The underlying assumptions for this paper's analysis are as follows:

Firstly, consider an economy with a single firm that generates stochastic cash flow, and there is no short sale.

Secondly, take reference from Bach and Christensen [24], who propose a consumption-based equity valuation model which adjusts forecasted residual income for risk rather than through a risk-adjusted cost of equity, the posterior discussion also use a fixed rate in the model and the numerical simulation because the potential risk has been considered in residual income.

Thirdly, there are two kinds of investors in the financial market, uninformed traders (percentage of shareholding is $1-\lambda_{t}$ ) and informed traders (percentage of shareholding is $\lambda_{t}$ ), with heterogeneous beliefs on the persistence of residual income from one period to the next, i.e. on parameter $w$. More explicitly, the uninformed investor believes that the persistence parameter is $w$, while informed investor's belief is $w+d_{t}$, where $0 \leq w+d_{t} \leq 1$ also applies, hence $d_{t}$ represents the level of 
heterogeneous beliefs to some extent between the two kinds of investors.

In addition, informed traders usually are institutional investors who have the capability and channel to get more private information, while uniformed traders are usually individual investors who don't have the superiority of information. This asymmetry is one of the main sources of heterogeneous beliefs, which lead to valuation difference, transaction and change of shareholding among investors.

Thus, the uninformed and informed investors' valuations of the equity are respectively

$$
\begin{gathered}
P_{t}^{1}=B_{t}+\frac{w}{1+r-w} X_{t}^{a} \\
P_{t}^{2}=B_{t}+\frac{w+d_{t}}{1+r-w-d_{t}} X_{t}^{a}
\end{gathered}
$$

Under the condition of risk neutral and market equilibrium, the stock price which equals to equity intrinsic value at date $t$ is

$$
\begin{aligned}
P_{t} & =\left(1-\lambda_{t}\right) P_{t}^{1}+\lambda_{t} P_{t}^{2} \\
& =B_{t}+\left[\frac{w}{1+r-w}+\frac{(1+r) \lambda_{t} d_{t}}{(1+r-w)\left(1+r-w-d_{t}\right)}\right] X_{t}^{a}
\end{aligned}
$$

Based on the signs of partial derivatives, the following propositions can be derived.

It can be obtained that

$$
\frac{\partial P_{t}}{\partial d_{t}}=\frac{(1+r) \lambda_{t}}{\left(1+r-w-d_{t}\right)^{2}} X_{t}^{a}
$$

Proposition 1: The relation between $P_{t}$ and $d_{t}$ depends on the sign of $X_{t}^{a}$, i.e.

(i) if $X_{t}^{a}>0$, stock price and heterogeneous beliefs have a positive relation;

(ii) if $X_{t}^{a}<0$, stock price and heterogeneous beliefs have a negative relation.

This means that if the residual income is positive, the higher the disagreement level between informed and uninformed traders is, the higher the stock price becomes, and vice versa.

It can be also acquired that

$$
\frac{\partial P_{t}}{\partial \lambda_{t}}=\frac{(1+r) d_{t}}{(1+r-w)\left(1+r-w-d_{t}\right)} X_{t}^{a}
$$

Proposition 2: The relation between $P_{t}$ and $\lambda_{t}$ vary in different circumstances, i.e.

(i) if $d_{t}>0$ and $X_{t}^{a}>0$, stock price and amount of informed investor have a positive relation;

(ii) if $d_{t}<0$ and $X_{t}^{a}<0$, stock price and amount of informed investor have a positive relation;

(iii) if $d_{t}>0$ and $X_{t}^{a}<0$, stock price and amount of informed investor have a negative relation; (iv) if $d_{t}<0$ and $X_{t}^{a}>0$, stock price and amount of informed investor have a negative relation.

As for proposition 2(i), when $d_{t}>0$, i.e. informed trader knows that there will be more residual income persist from period $t-1$ to $t$, i.e. more recurring income in the period $t-1$, (or higher percentage of the recurrent income in total income, or lower percentage of the non-recurring income in total income). If $X_{t}^{a}>0$ holds at the same time, then stock price and amount of informed investor have a positive relation. For other situations 2(ii), 2(iii), and 2(iv), the implications are similar.

It can be further achieved that

$$
\frac{\partial^{2} P_{t}}{\partial d_{t} \partial \lambda_{t}}=\frac{(1+r)}{\left(1+r-w-d_{t}\right)} X_{t}^{a}
$$

The above formula implies that the sign of the mixed partial derivative depends on the sign of $X_{t}^{a}$, thus the following proposition can be derived.

Proposition 3: The interaction effect of heterogeneous beliefs and informed trading on stock price depends on firm's residual income.

Proposition 1-3 identify that if informed traders get the information that there is a high possibility of positive residual income, and the actual residual income is also positive, they will submit more buying orders and hence stock price increases, and vice versa. In contrast, if informed traders get the information that there is a high possibility of positive residual income, while the real residual income is negative, the stock price will no doubt decrease, and vice versa.

Since institutional investors have the advantages of getting more information, it is a proxy for informed traders. Thus, the implications in Proposition 2-3 are in consistent with the findings of Dhaliwal et al. [25], who discussed the relation between institutional ownership, financial health, and the market valuation weights on earnings and the book value of equity.

\section{Numerical Simulation}

Based on the above propositions and according to some existing statistical and empirical literature, the related parameters are accordingly chosen for numerical simulation. Assume the equity book value per share is standardizes as $B_{t}=1$, the required rate of return is $r=5 \%$, informed trader's percentage of shareholding is $0 \leq \lambda_{t} \leq 1$, the persistence of residual income from one period to the next is $0 \leq w \leq 1$ for uninformed investors, while informed investor's belief is $0 \leq w+d_{t} \leq 1$, the heterogeneous beliefs is $-1 \leq d_{t} \leq 1$, and the residual income is $-3 \leq X_{t}^{a} \leq 3$. The simulation results are shown below. 


\subsection{The Effect of Heterogeneous Beliefs on Stock Price with Different Level of Residual Income}

Figure 1 shows the effect of heterogeneous beliefs on stock price at different levels of residual income.

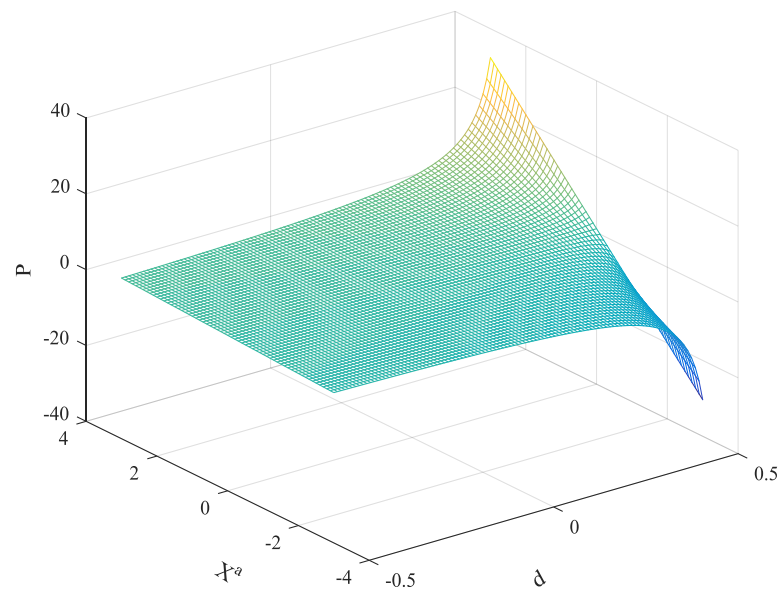

Figure 1. The effect of heterogeneous beliefs on stock price

It can be seen from Figure 1 that, when there is a positive residual income, i.e. $X_{t}^{a}>0$, the stock price has a positive relation with heterogeneous beliefs; while if there is a negative residual income, i.e. $X_{t}^{a}<0$, stock price and heterogeneous beliefs have a negative relation. Hence, it proves the Proposition 1.

\subsection{The Effect of Informed Trading on Stock Price with Different Level of Heterogeneous Beliefs}

Figure 2 shows the effect of informed trading on stock price at different residual income level when the heterogeneous belief is positive.

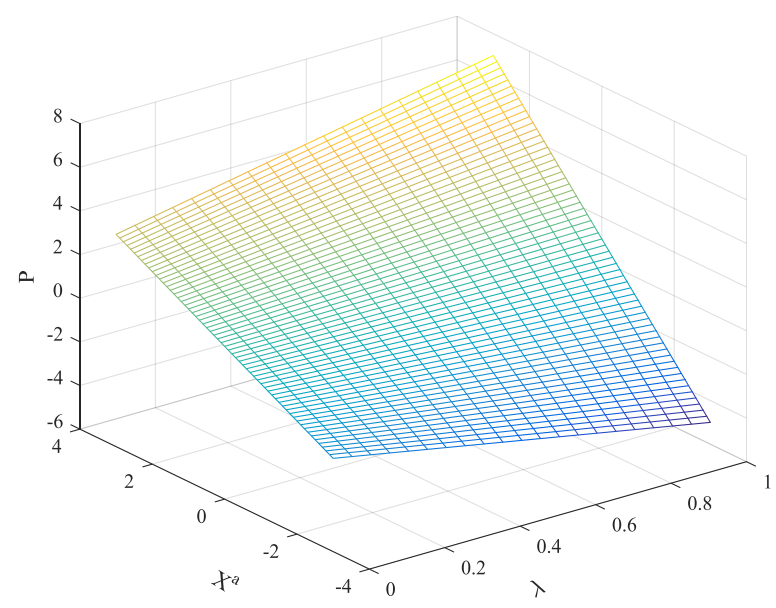

Figure 2. The effect of informed trading on stock price when $d_{t}>0$

It can be validated from Figure 2 that with positive heterogeneous beliefs, i.e. $d_{t}>0$, when the residual income is above zero, i.e. $X_{t}^{a}>0$, stock price and amount of informed investor have a positive relation; while if the residual income is less than zero, i.e. $X_{t}^{a}<0$, stock price and amount of informed investor have a negative relation. Thus, it verifies the Proposition 2(i) and 2(iii).

Figure 3 shows the effect of informed trading on stock price at different residual income level when the heterogeneous belief is negative.

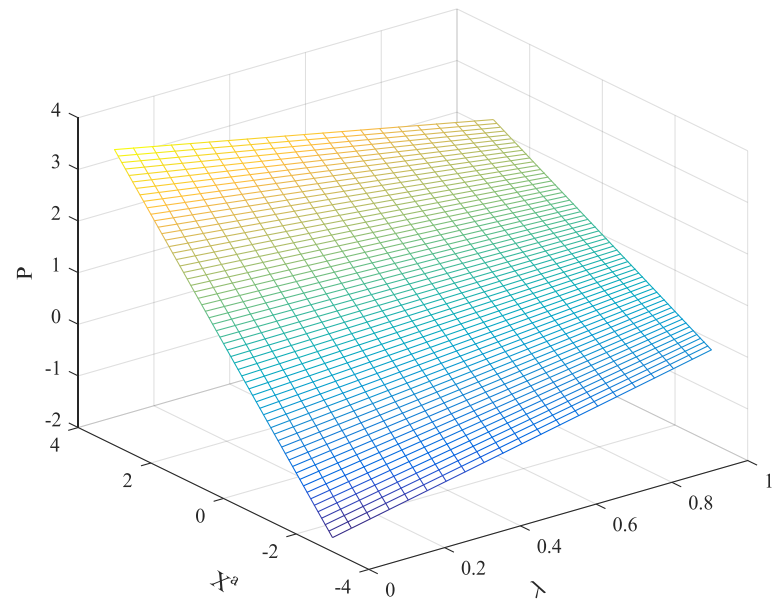

Figure 3. The effect of informed trading on stock price when $d_{t}<0$

It can be seen from Figure 3 that with negative heterogeneous beliefs, i.e. $d_{t}<0$, when the residual income is above zero, i.e. $X_{t}^{a}>0$, stock price and amount of informed investor have a negative relation; while if the residual income is below zero, i.e. $X_{t}^{a}<0$, stock price and amount of informed investor have a positive relation. Therefore, it confirms the Proposition 2(ii) and 2(iv).

\subsection{The Effect of Informed Trading and Heterogeneous Beliefs on Stock Price with Different Level of Residual Income}

Figure 4 shows the effect of informed trading and heterogeneous beliefs on stock price when the residual income is positive (i.e. $X_{t}^{a}>0$ ).

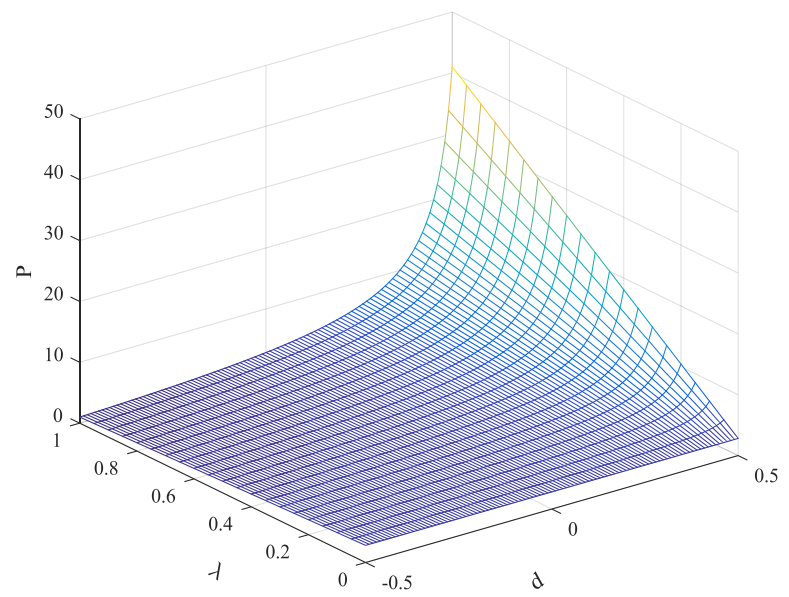

Figure 4. The effect of informed trading and heterogeneous beliefs on stock price when $X_{t}^{a}>0$ 
It can be seen from Figure 4 that, when the residual income is positive, i.e. $X_{t}^{a}>0$, the interaction of heterogeneous beliefs and informed trading has a positive effect on the stock price, and consequently, it proves the Proposition 3.

Figure 5 shows the effect of informed trading and heterogeneous beliefs on stock price when the residual income is negative (i.e. $X_{t}^{a}<0$ ).

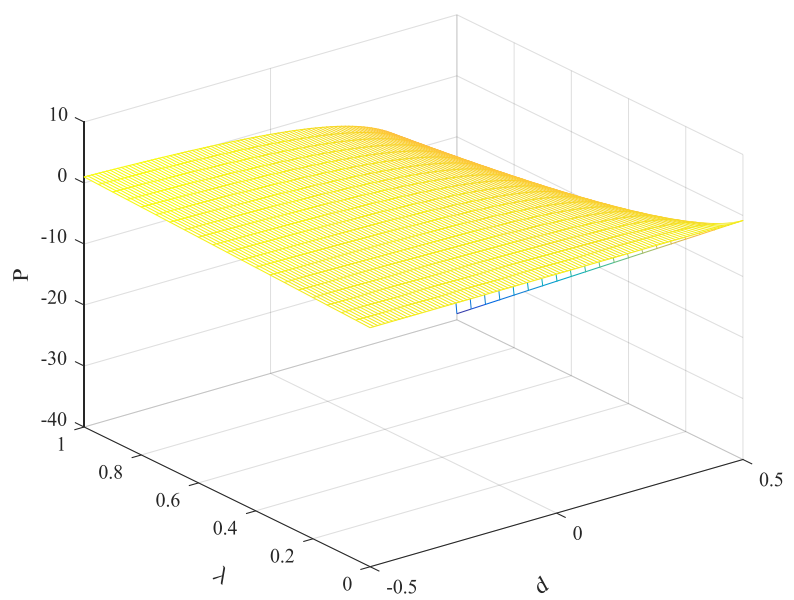

Figure 5. The effect of informed trading and heterogeneous beliefs on stock price when $X_{t}^{a}<0$

It can be seen from Figure 5 that when the residual income is negative, i.e. $X_{t}^{a}<0$, the interaction of heterogeneous beliefs and informed trading has a negative effect on the stock price, and hence verifies the Proposition 3.

Figure 6 shows the comprehensive effects of heterogeneous beliefs, informed trading, and residual income on the stock price.

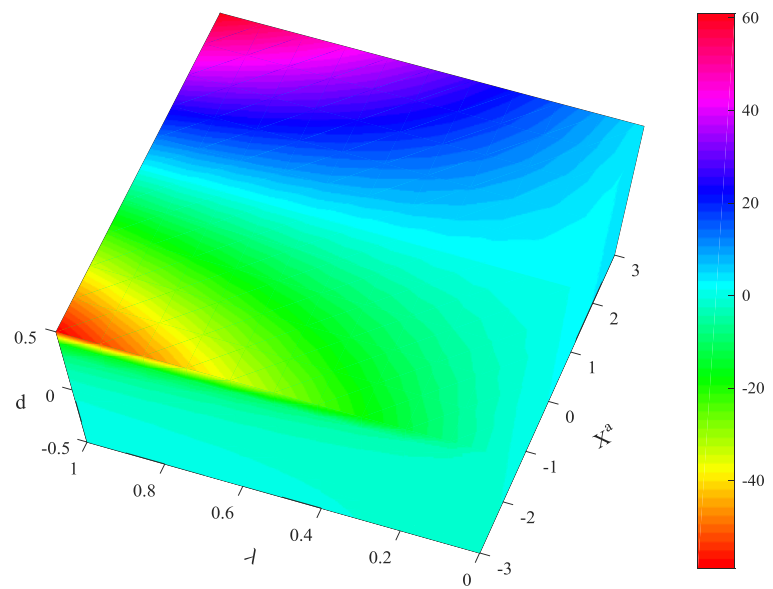

Figure 6. The comprehensive interaction effects of heterogeneous beliefs, informed trading and residual income on stock price

It can be seen from Figure 6 that when the residual income is positive, the higher the heterogeneous beliefs and informed trading are, the higher the stock price will be; while if the residual income is negative, the higher the heterogeneous beliefs and informed trading is, the lower the stock price becomes.

\section{Conclusions}

The paper extends the traditional residual income model by incorporating investors' heterogeneous beliefs on the persistence of residual income under some strict assumptions. Theoretical findings imply that the relation between stock price and heterogeneous beliefs depends on the sign of residual income, besides, informed trader also has an impact on stock price, but it depends on the interaction effect of heterogeneous beliefs and residual income.

The numerical simulation results prove that under the circumstance of positive heterogeneous beliefs, if residual income is also positive, stock price has a positive relation with heterogeneous beliefs and amount of informed investor, and vice versa; while if residual income is negative, stock price has a negative relation with heterogeneous beliefs and informed trading, and vice versa. On the contrary, the direction of influence is reversed under the circumstance of negative heterogeneous beliefs.

The discussion provides some valuable theoretical groundwork on the effect of heterogeneous beliefs on stock price through residual income and informed trading. Further research may propose a new RIM when investors are loss averse, which will be more realistic.

\section{Acknowledgements}

This work is supported by The Humanities and Social Science Research Project of Ministry of Education of China (Grant No. 17YJC630108), Teacher's research seed plan in BISU, and Beijing Natural Science Foundation (Grant No. 9174033).

\section{REFERENCES}

[1] Ohlson, J. A.. Earnings, book values, and dividends in security valuation. Contemporary Accounting Research, 1995, Vol. 11, No. 2, 661-687.

[2] Feltham, G. A., Ohlson, J. A.. Valuation and clean surplus accounting for operating and financial activities. Contemporary Accounting Research, 1995, Vol. 11, No. 2, 689-731.

[3] Feltham, G. A., Ohlson, J. A.. Uncertain resolution and the theory of depreciation measurement. Journal of Accounting Research, 1996, Vol. 34, No. 2, 209-234.

[4] Richardson, G., Tinaikar, S. Accounting based valuation models: what have we learned? Accounting \& Finance, 2004, 
Vol. 44, No. 2, 223-255.

[5] Zhang Guochang. Accounting Information and Equity Valuation: Theory, Evidence, and Applications. Springer, 2014.

[6] Shleifer, A.. Inefficient markets: An introduction to behavioral finance, Oxford University Press, UK, 2000.

[7] Xiong, W.. Bubbles, crises, and heterogeneous beliefs. NBER Working paper No. 18905, 2013.

[8] Hong, H., Stein, J. C.. Disagreement and the stock market. Journal of Economic Perspectives, 2007, Vol. 21, 109-128.

[9] Huang, D., Li, J., Wang, L.. Are disagreements agreeable? Evidence from information aggregation. Journal of Financial Economics, article in press, 2021. https://doi.org/10.1016/j.jfineco.2021.02.006

[10] Gilchrist, S., Himmelberg, C. P., Huberman, G.. Do stock price bubbles influence corporate investment? Journal of Monetary Economics, 2005, Vol. 52, No. 4, 805-827.

[11] Smith, J.. Does the market matter for more than investment? Journal of Empirical Finance, 2014, Vol. 25, No. 3, 52-61.

[12] Buraschi, A., Trojani, F., Vedolin, A.. Economic uncertainty, disagreement, and credit markets. Management Science, 2014, Vol. 60, No. 5, 1281-1296.

[13] Baker, S. D., Hollifield, B., Osambela, E.. Disagreement, speculation, and aggregate investment. Journal of Financial Economics, 2016, Vol. 119, No. 1, 210-225.

[14] Siganos, A., Vagenas-Nanos, E., Verwijmeren, P.. Divergence of sentiment and stock market trading. Journal of Banking and Finance, 2017, Vol. 78, 130-141.

[15] Curatola, G.. Optimal portfolio choice with loss aversion over consumption, The Quarterly Review of Economics and Finance, 2017, Vol. 66, 345-358.
[16] Borovička, J.. Survival and long-run dynamics with heterogeneous beliefs under recursive preferences. Journal of Political Economy, 2020, Vol. 128, No. 1, 206-251.

[17] Pohl, W., Schmedders, K., Wilms, O.. Asset pricing with heterogeneous agents and long-run risk. Journal of Financial Economics, article in press, 2021.https://doi.org/10.1016/j.j fineco.2021.01.005

[18] Baker, M., Wurgler, J.. Market timing and capital structure. Journal of Finance, 2002, Vol. 57, No. 1, 1-32.

[19] Shleifer, A., Vishny, R. W.. Stock market driven acquisitions. Journal of Financial Economics, 2003, Vol. 70, No. 3, 295-311.

[20] Li, W., Lie, E.. Dividend changes and catering incentives. Journal of Financial Economics, 2006, Vol. 80, No. 2, 293-308.

[21] Denis, D. J., Osobov, I.. Disappearing dividends, the earned / contributed capital mix, and catering incentives: International evidence on the determinants of payout policy. Journal of Financial Economics, 2008, Vol. 89, 62-82.

[22] Butler, A. W., Cornaggia, J., Grullon, G., Weston, J. P.. Corporate financing decisions, managerial market timing, and real investment. Journal of Financial Economics, 2011, Vol. 101, No. 3, 666-683.

[23] Jung, H. W., Subramanian, A.. Capital structure under heterogeneous beliefs. Review of Finance, 2014, Vol. 18, No. $5,1617-1681$

[24] Bach, C., Christensen, P. O.. Consumption-based equity valuation. Review of Accounting Studies, 2016, Vol. 21, 1149-1202.

[25] Dhaliwal, D.S., Li, Z., Xie, H.. Institutional Investors, Financial Health, and Equity Valuation. Asia-Pacific Journal of Accounting \& Economics, 2010, Vol. 17, No. 2, 151-173. 